Article

\title{
The Legitimacy, Accountability, and Ownership of an Impact-Based Forecasting Model in Disaster Governance
}

\author{
Sterre Bierens ${ }^{1}$, Kees Boersma ${ }^{1, *}$ and Marc J. C. van den Homberg ${ }^{2}$ \\ ${ }^{1}$ Department of Organization Sciences, Faculty of Social Sciences, Vrije Universiteit Amsterdam, 1105 De Boelelaan, \\ The Netherlands; E-Mails: sterrebierens@gmail.com (S.B.), f.k.boersma@vu.nl (K.B.) \\ 2 510, an initiative of the Netherlands Red Cross, 2593 HT The Hague, The Netherlands; \\ E-Mail: mvandenhomberg@redcross.nl \\ * Corresponding author
}

Submitted: 15 April 2020 | Accepted: 8 June 2020 | Published: 10 December 2020

\begin{abstract}
The global shift within disaster governance from disaster response to preparedness and risk reduction includes the emergency of novel Early Warning Systems such as impact based forecasting and forecast-based financing. In this new paradigm, funds usually reserved for response can be released before a disaster happens when an impact-based forecast-i.e., the expected humanitarian impact as a result of the forecasted weather-reaches a predefined danger level. The development of these impact-based forecasting models are promising, but they also come with significant implementation challenges. This article presents the data-driven impact-based forecasting model as developed by 510, an initiative of the Netherlands Red Cross. It elaborates on how questions on legitimacy, accountability and ownership influenced the implementation of the model within the Philippines with the Philippine Red Cross and the local government as the main stakeholders. The findings imply that the exchange of knowledge between the designer and manufacturer of impact-based models and the end users of those models fall short if novel Early Warnign Systems are seen as just a matter of technology transfer. Instead the development and implementation of impact based models should be based on mutual understanding of the users' needs and the developers of such models.
\end{abstract}

\section{Keywords}

accountability; disaster governance; early warning systems; forecast based financing; legitimacy; ownership; power relations; risk reduction

\section{Issue}

This article is part of the issue "The Politics of Disaster Governance" edited by Dorothea Hilhorst (Erasmus University Rotterdam, The Netherlands), Kees Boersma (Vrije Universiteit Amsterdam, The Netherlands) and Emmanuel Raju (University of Copenhagen, Denmark).

(C) 2020 by the authors; licensee Cogitatio (Lisbon, Portugal). This article is licensed under a Creative Commons Attribution 4.0 International License (CC BY).

\section{Introduction}

Due to climate change, globalization, and rapid urbanization, the impact of natural hazards on local communities in terms of the number of casualties and damage to critical infrastructures is increasing, thereby threatening social and economic welfare (Dongeren et al., 2014; Mechler et al., 2014). In recent policies, early warning systems (EWS) are an essential component of disaster risk reduction (DRR) measures, and the benefits of EWS have been widely addressed in the Hyogo Framework for Action 2005-2015 (UNISDR, 2015a) and the Sendai Framework on DRR (UNISDR, 2015b). The advantage of focusing on EWS instead of response has been confirmed by an extensive body of research (Aitsi-Selmi, Sasaki, Wannous, Murray, \& Egawa, 2015; De Perez et al., 2015; Dongeren et al., 2014; Frazier, Walker, Kumari, \& Thompson, 2013; UNEP, 2012). Hence, adopting EWSs can reduce fatalities and economic loss (Rai, van den Homberg, Ghimire, \& McQuistan, 2020) and can result 
in increased local resilience (Rogers \& Tsirkunov, 2010; UNISDR, 2013).

Currently, modern EWSs rely on technological innovations regarding data analytic techniques and communication systems (Cools, Innocenti, \& O'Brien, 2016) to allow new possibilities in forecasting. Whereas forecasting traditionally focuses on predicting hazardous weather, like high wind speeds or heavy rainfall, new innovative methods focus on forecasting the hazard's impact on different societal sectors such as the agricultural, health, or humanitarian sectors. According to the World Meteorological Organization's (2015) Guidelines on Multi Hazard Impact-Based Forecast and Warning Services and the Red Cross's trigger methodology (Red Cross, 2018), 'impact-based forecasting' describes the relationship between the magnitude of the forecasted hazard (input) and the resulting impact (output). The modelling of this relationship requires input on exposure, that is, the situations of people, infrastructure, housing, production capacities, and other tangible human assets located in hazard-prone areas, and vulnerability, the susceptibility of an individual, communities, assets, or systems to the impacts of hazards (UNDRR, 2020).

In this context, 'forecast-based financing' (De Perez et al., 2015) is an approach that is operationalizing impact-based forecasting in the humanitarian domain. Such financing supports with EWSs, which allow individuals and communities a window of time for action. For time-critical events such as tsunamis, hurricanes, mudslides, and flash floods, the warnings are a trigger to action-to move quickly out of the danger area. Forecastbased financing initiatives based on this principle started within the Red Cross Red Crescent Movement in 2013 and are being rolled out in over 36 countries. Within forecast-based financing, the release of funds takes place when an impact-based forecast-the expected humanitarian impact resulting from the expected weatherreaches a predefined danger or trigger level. Funding is released according to an approved early action protocol that stipulates the trigger and the early actions that will be funded to support the communities to be affected.

In this article, we explore the design, transfer, and implementation of a forecast-based financing method for typhoons in the Philippines and zoom in on the impact-based forecasting model developed by 510 , a Netherlands Red Cross initiative. 510 is developing models for different hazards (floods, typhoons, drought) for different developing countries. Its mission is to shape the future of humanitarian aid by converting raw data into information that can be used for local interventions, and putting that information in the hands of humanitarian aid workers, decision makers, and people affected so they can better prepare for and cope with disasters and crises. The assumption is that smart use of (big) data will result in faster and more (cost-)effective humanitarian aid. 510 focuses on supporting Red Cross National Societies in developing countries, and it has currently assisted 33 National Societies.
Despite the seemingly clear benefits of EWS instruments, the design, transfer, and implementation of interventions such as forecast-based financing are challenging (Basher, 2006; Frazier et al., 2013). International humanitarian sector interventions often neglect the importance of power relations (Barnett, 2013; Mulder \& Boersma, 2017; Mulder, Ferguson, Groenewegen, Boersma, \& Wolbers, 2016; Ossewaarde, Nijhof, \& Heyse, 2008). Following Steffek and Hahn (2010), we study power relations using legitimacy, accountability, and ownership as analytical lenses, each of which frames barriers to adopting interventions in particular ways (Biesbroek, Termeer, Klostermann, \& Kabat, 2014). We believe that gaining deeper understanding of power relations will contribute to the effectiveness and efficiency of humanitarian interventions (Alcayna, Bollettino, Dy, \& Vinck, 2016; van den Homberg \& McQuistan, 2019). Here, we will address the following question: What is the role of legitimacy, accountability, and ownership in the design, transfer, and implementation process of 510's impact-based forecasting model in the Philippines?

\section{Forecast-Based Financing as Innovation: The Impact of Power on Humanitarian Interventions}

Humanitarian interventions take place in the context of humanitarian governance in which Western humanitarian organizations are dominant and the capacities of local communities are often neglected or at least underestimated (Barnett, 2013; Barnett \& Duvall, 2005; Frazier, et al., 2013; Narkunas, 2015). Yet, for humanitarian interventions to be both fitting and sustainable, local knowledge, experience, and demands have to be taken into account. This way, humanitarian interventions-such as EWSs - can strengthen local resilience, defined as "the ability of a system, community or society exposed to hazards to resist, absorb, accommodate to and recover from the effects of a hazard in a timely and efficient manner" (Alcayna et al., 2016, p. 2), especially if the so-called last mile, that is the final stage of a humanitarian relief chain (Balcik, Beamon, \& Smilowitz, 2008), is reached. To this end, international organizations such as UNDRR and World Meteorological Organization as well as NGOs have developed people-centred, EWS approaches to ensure EWSs are community based or preferably even community managed (Ewbank, Perez, Cornish, Worku, \& Woldetsadik, 2019; Maskrey, 2011). Many modern EWSs, especially their monitoring and warning components, require extensive atmospheric modelling and are based on technological interventions (Zschau \& Küppers, 2013). The 510 impact-based forecasting model is no exception. In this study of technology-driven EWSs, we will look at not just the product of technology itself but the product of the interplay between technology and social power relations.

Power relations and technology are mutually constitutive: Power relations shape technology and technology shapes power relations (Williams \& Edge, 1996). 
We see the impact of power relations on EWSs, first, as a matter of legitimacy, the perception that humanitarian organizations' actions are "desirable, proper or appropriate within their institutional environment" (Ossewaarde et al., 2008, p. 43). Second, by addressing power relations, we include the accountability issue of humanitarian interventions. Accountability refers to the reasons why a humanitarian intervention is necessary and to how humanitarian organizations or governments take responsibility for vulnerable aid receipients (Ossewaarde et al., 2008). This analytical lens studies the consequences of both upward and downward accountability (Ebrahim, 2003; Unerman \& O'Dwyer, 2010). Lastly, our analysis of power relations addresses the question of representation or ownership, that is, the question of whether or not (international) humanitarian organizations allow local organizations and communities to initiate, influence, or lead humanitarian interventions.

Following the resilience humanitarianism debate, in which local communities and local response mechanisms are central (Baharmand, Boersma, Meesters, Mulder, \& Wolbers, 2016; Bankoff, Frerks, \& Hilhorst, 2004; Hilhorst, 2018), we studied the role of 510's impact-based forecasting model in shaping the early action interventions of forecast-based financing in the Philippines. The central intervention in this article is early community-support actions such as cash transfers and distributions of house strengthening kits. Our study is based on the idea that user-centred design processes (Von Hippel, 2005) in interventions can partially fill the gap in how humanitarian actions are contextualized. User-centred design is the process in which the designers' focus is on the users and their needs in each phase of the design process. Projects based on local knowledge and involvement have been proven to match the users' needs more accurately, and they are more sustainable in the long run (Battista \& Baas, 2004; Dekens, 2007).

To answer the pressing demand for legitimacy, accountability, and local ownership, humanitarian organizations have increasingly started to shift the design, planning, and execution of an intervention (in this case, forecast-based financing) to the local beneficiary, introducing a 'collaborative design process' in which the expertise and needs of the beneficiary is central (Santos, Capet, \& Diehl, 2013). The tendency to centralize the beneficiary - or 'user' - of humanitarian response is in line with the business world's tendency to centralize the user in product and service design (Von Hippel, 2005) and with insights from the international technology transfer literature. For the transfer of technology to be successful, the recipient's views and demands and the domestic production methods and management styles must be included in the technology's design (Choi, 2009; Maskus, 2004). Besides including technical aspects such as information accuracy and standardization, technology transfer should include organizational support and capacity building (Nahar, Lyytinen, Huda, \& Muravyov, 2006). In our study, technology transfer takes place at differ- ent levels: Within the Red Cross Red Crescent Movement, between 510 and the Philippine Red Cross, and possibly at some later stage, between the Philippine Red Cross and the Philippine Atmospheric, Geophysical, and Astronomical Services Administration. Technology is also transferred from the national to the local level. The level of transfer required depends on the type of impactbased forecasting model. For example, the impact-based forecasting model for floods in the Philippines operates at the scale of a river basin, and local actors working on flood forecasting and warning are involved in model development. However, the model for typhoons works at the national scale, where it is more important that local stakeholders trust the model's outcomes and can work with the forecasts than it is that there is a transfer of machine learning expertise.

Despite the shift to collaborative design processes, the user is often still seen as the recipient rather than a partner in the design, transfer, and implementation of technology. That means the designer and manufacturer fail to understand the full context of the user's demands. In addition, products and interventions resulting from user-centred design processes still might not fit the specific context in which they will be implemented (Madianou, Longboan, \& Ong, 2015). Therefore, coownership and co-creation of the technology should be emphasized in every stage of the process, thereby resulting in higher degrees of acceptance and use (Sleeswijk Visser, Van der Lugt, \& Stappers, 2007). In our study, we use the lenses of legitimacy, accountability, and ownership to investigate the degree of co-ownership and cocreation in 510's impact-based forecasting model.

\section{Methodology and Approach}

This article is based on a qualitative, interpretative approach that enabled us to study and understand the meaning-making activities of those who have been involved in the design, transfer, and implementation of 510's impact-based forecasting model (Bryman, 2012; Yanow \& Schwartz-Shea, 2015). We zoomed in and out between local data and context, on the one hand, and our research findings and theory, on the other. This resulted in an iterative process in which we adjusted the course of research throughout the research period, switching our focus between research findings and theoretical context. Using a grounded approach, we alternated between theory and data to adequately represent the complexity of the situation and to develop a coherent analysis (Gioia, Corley, \& Hamilton, 2013; Strauss \& Corbin, 1990).

The data was collected by interviews and participant and non-participant observations (in the Philippines and the Netherlands), document analysis (background information on the impact-based forecasting model and the forecast-based financing program), and focus group discussions (the Philippines). Part of the research was based on an ethnographic approach (Hammersley \& Atkinson, 
2007) used to understand the broader context of humanitarian interventions and the personal perspectives of the involved stakeholders. To gain insights into the personal perspectives of the stakeholders, we observed their behaviour in organizational settings. We attended several meetings in the Netherlands Red Cross office in the Hague, during which the model was discussed. In the Philippines, we conducted ten rounds of interviews with individuals and groups. Interviewees were selected both on their availability and on their position in the forecastbased financing program in order to involve as many different stakeholders as possible from different organizational positions and roles (both staff and management positions).

We organized two focus group discussions (Parker \& Tritter, 2006) in which a co-design process was set up. Within the resulting co-design sessions, participants were asked questions about digital literacy, the process of disaster response, and their "ideal natural hazard information dashboard." The participants could not only to include or refer to formal information sources but also to use their own experiences and perceptions to picture what information they would ideally receive in a realcase situation. By making use of co-design sessions in our research, the (non-designer) users of the model got the chance to articulate design proposals and provide starting points for subsequent professional (re)development of the designing work (Sanders, Brandt, \& Binder, 2010). The information obtained by the co-design sessions was used to assess the front-end design of the impact-based forecasting model, and to illuminate the position of the participants towards an impact-based forecasting model in general. The two co-design sessions took place with approximately 15-20 participants (some leaving or arriving half way within a given session). In the first codesign session, held in Tacloban, all participants were of Filipino descent and from different governmental institutions and NGOs. In the second co-design session, held in the Philippine Red Cross headquarters in Manila, all participants were affiliated with the Red Cross, and six were from foreign Red Cross National Societies, including France, Australia, Spain, and Germany. Participants discussed the questions freely while we observed them, and they created a dashboard, which we collected afterwards. The interviews and focus group discussions were recorded with the interviewees' consent and later transcribed and categorized.

The grounded approach involved the exploration of research categories and the relationships between categories, whichled to plausibility of arguments and conclusions. During the analysis, we continuously created and confirmed categories, following an iterative process, weaving back and forth between the data (collection), emerging theoretical concepts, and theoretical sampling. Research findings were initially categorized according to concepts that recurred continuously throughout the interviews. These preliminary categories corresponded to the language and terms participants used, which were thus classifiable as 'in vivo' concepts (Ritchie, Lewis, McNaughton Nicholls, \& Ormston, 2013). Those concepts were closely related to respondents' life world experiences with disasters and disaster response and with their role in the Philippine response system. Next, the in vivo concepts were generalized into broader categories (Gioia et al., 2013) corresponding to the three categories of the resilience humanitarianism debate: legitimacy, accountability, and local ownership. To determine which category each in vivo concept applied to, we defined the categories and evaluated the context of the research findings. The research findings are grouped in the sections below. The selected quotes were chosen to illustrate the way various actors made sense of and gave meaning to the design, transfer, and implementation of 510's impact-based forecasting model.

\section{Findings}

\subsection{Setting the Scene}

The Philippines is ranked third on the World Risk Index 2018 (Heintze et al., 2018). Natural hazards there include earthquakes, flooding, landslides, volcanic eruptions, and droughts. On average, three to four typhoons (tropical cyclones) a year make landfall in the Philippines. Since Typhoon Yolanda (Haiyan) took 6,000 lives in 2013, the Philippines government has invested heavily in the communication aspect of disaster warning systems and in DRR strategizing, measuring success on a 'zero casualty' policy (UNISDR, 2015a). Because of its heavy exposure to natural disasters and national investments in DRR, the Philippines was labeled as an 'expert' in DRR by the UN (UNISDR, 2015a). The key governmental agency for the impact-based part of forecast-based financing is the Philippine Atmospheric, Geophysical, and Astronomical Services Administration, a member agency of the National Disaster Risk Reduction and Management Council; the Philippine Atmospheric, Geophysical, and Astronomical Services Administration is the national meteorological and hydrological services agency mandated by the government to provide natural hazard prediction and weather forecasting (Blanco, 2015).

Despite the decentralization in the Philippines, the national government still plays an important role in the methods local government units use for DRR strategizing (Blanco, 2015). It has implemented controlling bodies, including the Commission of Audit, which annually inspects how each local government unit has allocated its budget. When a local unit has made budgetary decisions that are not in line with the national government's general guidelines, it is held accountable and can suffer severe sanctions, including monetary or legal consequences. Similarly, consequences can be levied when a local unit decides to follow a forecast other than the Philippine Atmospheric, Geophysical, and Astronomical Services Administration's and thus is not able to account for whether it spent money on anticipatory humanitarian 
actions. Although many existing laws support the decentralization of disaster governance and mandate local government units, the decentralization of resources to local units is still a challenge. At the same time, decentralization has also led to the further entrenchment of traditional elites and their local allies, and citizen participation and accountability have not necessarily led to the redistribution of power. Local officials, such as mayors and government officials, have shaped a seemingly accountable, participatory, and empowered governance structure by "forging collaborative partnerships with civil society organizations and the private sector, while they are reinforcing their political dominance as, in actuality, these partnerships can weaken civil society" (Porio, 2017, p. 32).

In this complex social and political context, the German Red Cross, funded by the German Foreign Federal Office, began implementing a forecast-based financing model. It appointed a forecast-based financing coordinator in mid-2017 who works at the Philippine Red Cross headquarters in Manila and who created a project plan in collaboration with its departments. The forecastbased financing project is working on a typhoon, flood, and drought early action protocol. The German Red Cross subcontracted 510 to develop an impact-based forecasting model for typhoons. The protocol works on the basis of a 'trigger': The warning of a time-critical event such as a hurricane. This trigger means that a predicted impact is reaching a pre-agreed upon threshold. For example, a trigger might be when the predicted impact on housing is the total destruction of more than $10 \%$ of houses in at least three municipalities. The early action protocol for typhoons defines the following four early actions, which will start once the trigger is reached and funding is released: (1) Protection of livelihoods through early harvesting of mature crops, (2) protection of livelihoods through the evacuation of livestock and assets, (3) installation of house strengthening kits, and (4) (crosscutting) basic needs provision through Cash for Work (Philippine Red Cross, 2019). With this forecast-based financing project, the German Red Cross initially aims at piloting and validating the proper functioning of forecastbased financing within the Philippine Red Cross only, but it subsequently aims to roll the project out across other governmental and humanitarian organizations to ensure sustainability.

\subsection{Legitimacy}

Our first step in assessing the legitimacy of 510's impactbased forecasting model was defining in which institutional environment forecast-based financing functions. Forecast-based financing is a multi-stakeholder process in which many UN, government, humanitarian agency, and private sector actors participate. The Philippine Red Cross is the primary agency responsible for the implementation of forecast-based financing. Its locallevel offices work as intermediaries between the financ- ing project team and the project's participants. Apart from the forecast-based financing project, several related projects are ongoing, such as those on DRR, resilience, and humanitarian responses. Partner National Societies, such as the German, Netherlands, and American Red Cross, support the Philippine Red Cross in these projects. For 510's initiatives in the Philippines, the German Red Cross is its direct counterpart and contractor, and the German Red Cross and the Philippine Red Cross orchestrate the local level's involvement.

Development of the impact-based forecasting model began in 2016 and was based on eliciting the needs of local organizations through key informant interviews in which $60 \%$ of 32 interviewed decision makers (government, NGOs, and UN) indicated that they needed a faster, more complete, and more objective analysis of priority areas with heavy damage and high numbers of people affected right after a typhoon made landfall (Van Lint, 2016). However, complex power relations can influence how the model is used in practice. For example, Philippine Red Cross executives might not always express the need for a data-driven model, because the model would impact their current decision-making process. Philippine Red Cross headquarters has an important voice in evaluating what area will suffer the highest impact during a natural disaster, but they never take this decision on their own. Decisions are based on a mixture of experience and consultation with local Philippine Red Cross chapter administrators, with whom the headquarters are always in contact during impending natural disasters. For example, before typhoon Tisoy made landfall in 2019, the Philippine Red Cross's decision to deploy its team was made with input from the head of the Disaster Management Services and the International Federation of the Red Cross country office. The current practice of the Philippine Red Cross is to send an anticipatory lump sum to all chapters that are most at-risk of an impending typhoon to help them initiate preparedness and rapid response actions.

However, the official field survey-based counts of a typhoon's impact typically do not arrive until a few weeks into the response. Therefore, 510 developed a priority index model that uses actual hazard data (collected after the typhoon made landfall) to predict where the most damage would be as a result of the typhoon that just made landfall. The model is trained on historical typhoons (29 by now). Weather forecasting predicts the whether in the future using data from previous events combined with temporal information and recent trends. When a forecast is made the typhoon forecast data for the new typhoon or-in the case of the priority index model - the data of the typhoon that made landfall is used. The impact-based forecasting model is different from the priority index model in that it uses the forecasted hazard data so that a forecast of the impact can be given from 72 hours before up to 6 hours before. The model's performance is expressed in standard machine learning performance metrics for either classification (confu- 
sion matrix) or regression (such as $\mathrm{R}^{2}$ and mean absolute error; Wagenaar et al., 2020). The model was also benchmarked against baselines, the most simple one being a coin toss and the slightly more complex ones being expert-based types of rule models. Since the initial model was only able to predict the damage to houses, 510 also developed a model predicting rice crop loss. However, crop loss data (output) from the Department of Agriculture was unavailable below the provincial lev$\mathrm{el}$, which constrained the implementation of that model (Boeke et al., 2019).

The usage of data-driven models in general was questioned by potential users. A local FAO employee worried about the usage of "heavy digital platforms" in the battle against natural disasters, as rural areas in the Philippines are almost always underrepresented in digitalization: "We use the tool for the greater good, but to be able to target the area to work with...imagine there are still areas that do not have hardware, they don't have a desktop, laptop, or mobile phone." He stressed that the people living in these areas are the 'poorest inhabitants' of the Philippines, and they are begin even further disadvantaged by the digitalization of humanitarian interventions. This concern was shared by local members of the Red Cross in Tacloban, who stated that, "our participants are not very technical in that way." This digital divide indeed negatively influences the understanding and potential uptake of anyimpact-based forecasting model.

Currently, this model produces predictions at the municipality level (indicating whether or not more than $10 \%$ of the houses will be destroyed entirely); it is therefore mostly used at the headquarter level to prioritize municipalities. Subsequent targeting of households within a municipality is done by barangay (neighbourhood) validation committees of local stakeholders, so without using a data-driven model from the outside. An additional constraint in supporting local communities is that any governmental intervention for preparedness/early action has to be based on an official forecast. As a Filipino technician employed by the forecast-based financing project explained:

For the technical side, we really need to have the PAGASA [Philippine Atmospheric, Geophysical, and Astronomical Services Administration] have ownership over it...from the start they need to be into it already, because ultimately it is not going to be a sustainable solution when the PAGASA says: "No, wait."

Indeed, organizations affiliated with the government are not required to take actionbased on impact-based forecasts coming from the Philippine Red Cross. The technician further explained the complexity of collaborating on forecast dissemination: "At the moment I am sensing some friction when we provided them [the Philippine Atmospheric, Geophysical, and Astronomical Services Administration] with the 510 model...since they are the mandated agency, of course it must be provided through them."

\subsection{Accountability}

The Philippine Red Cross, as legally stipulated in a Republic Act, is an auxiliary to the Philippine government in the humanitarian domain. It can disseminate information to communities that will be affected and support them in taking early actions to protect themselves. Currently, local government units can use their Quick Response Funds for disaster response only once a disaster has already happened, instead of on the basis of a forecast. However, the policy document, Memorandum 60: Revised Guidelines for the Declaration of a State Calamity (NDRRMC, 2019), published 17 June 2019, states that local government units can use their Quick Response Funds in response to a forecast if they can predict that at least $15 \%$ of their population will be affected. This policy is not yet operationalized, but once its implementing rules are clarified, the Quick Response Funds can be used for forecast-based responses. How the forecast has to be done or by whom has not yet been explained, but an ad hoc governmental committee has been formed to develop guidelines. Although numerous laws, policies, and legislations are in place to enable local units to take an active role in disaster response, much of the resources and decision-making power still remain with the national government. In addition, we observed that humanitarian organizations other than the Red Cross had different ideas about forecastbased financing. As an interviewee from one such organization explained: "I don't think...on our end that it's [forecast-based financing] using an impact-based model or an impact-based forecast...it's still based on how the government structures the forecast."

In this complex institutional context, several dialogue platforms in which many actors participated were set up prior to starting the forecast-based financing project. However, an explanation of how to develop and use an impact-based forecasting model was rarely included in the forecast-based financing dialogue platforms and trainings. As the model required a minimum of data and digital literacy, explanations focused on more general forecastbased financing topics instead. The gap in understanding between forecast-based financing as an intervention and impact-based forecasting as the technical modelling part of that intervention proved to be problematic during the transfer and implementation of the process. It led to confusion in the Red Cross headquarters in Manilla, and it caused difficulties at the local level, where local stakeholders shaped the project without a proper idea of how the impact-based forecasting model worked or what it could mean for them. It was not clear to them that the model would provide triggers at the municipality level only and not at the household level. In addition, it became clear during the implemention process that a proper understanding and communication of what the model can and 
cannot do was lacking. This lack of understanding made accountability (i.e., questions of what decisions are being made, by whom, and for whom) problematic.

\subsection{Local Ownership}

The dialogue platforms mentioned in the previous section led to the formation of three working groups focused on financing, early action, and triggers. The Technical Working Group for the triggers included Manila government, UN, NGO, and Red Cross participants. The aim of each working group was to exchange knowledge and ideas about the concept of forecastbased financing and to implement local stakeholders' interests in the impact-based forecasting model. The model, based on a machine learning model in software code, requires skilled data experts. To go from piloting to full implementation within the Philippine Red Cross Operations Center, this backend (the software code) had to be complemented with a frontend that allows usage of the model by people with fewer technical data skills. To increasingly involve local ownership, 510 organized co-design sessions with local stakeholders. These sessions were set up in an attempt to meet the demands of the collaborative design process (Santos et al., 2013; Von Hippel, 2005). However, since the designing of the model had already been done in the Hague prior to assessing the local context, the co-design sessions resulted in incremental changes that could only partly solve the problems the end-users faced.

Not only was the transfer and implementation of technology complex because it was developed elsewhere, but the structural institutional constraints in the Philippines also impeded local ownership. Due to the high number of (foreign) humanitarian organizations and initiatives in the Philippines, it is hard to maintain any form of supervision over 'who does what.' As one interviewee argued:

The problem is that each one [NGOs] is doing their own thing differently...developing their own model...the issue there is that it should be harmonized....There are projects doing DRM [disaster risk management] work that are not coherent to the model and the approach of the government, so it creates conflict.

Therefore, mandated organizations, such as the Philippine Atmospheric, Geophysical, and Astronomical Services Administration, are perceived as an attempt of the Philippine government to maintain a form of local ownership over humanitarian organizations and interventions. This restricts potential users with governmental ties from implementing a foreign forecasting model. For example, if a local governmental unit has DRR expenses that are unaligned with the 'official forecast' disseminated by the Philippine Atmospheric, Geophysical, and Astronomical Services Administration and approved by the Commission of Audit, it can suffer monetary or legal prosecution. As one interviewee stated: "If impact-based forecasting is piloted, the way forward from here is really to get the buy-in of the national government."

The lack of government support for 510's impactbased forecasting model in the Philippines further constrained transfer and implementation efforts, and eventually, usage of the model on a wider scale. Because of extensive local experience regarding natural hazards, potential users trust their own experience and expertise more than predictions from a foreign-designed model. A Philippine Red Cross technical advisor stated: "It is okay for me to use different models....But I want to see a validation report. I want to see the accuracy.... I think it is important to somehow incorporate local experience into the model." He explained that once a local humanitarian organization decides to use a forecasting model, the actions they undertake become their responsibility. Therefore, organizations such as the Philippine Red Cross often choose to stick with their current procedures to ensure they do not make mistakes based on unvalidated models.

Continuous communication with local stakeholders about what is technically possible and how the different versions of models are evolving has proven difficult. As a Filipino technical advisor of the Red Cross argued, potential users were 'very excited' when they first heard about 510's impact-based forecasting model and its potential usage, but they simultaneously questioned the variables used in the model. He stated: "They were saying, 'Can you do this further for agricultural impact?'...for agriculture, they are interested in the damage to the crops and also for the lack of food security." Furthermore, it became clear that the impact associated with a typhoon is not due to only one damaging mechanism such as the initial high wind speeds; it is also linked to consecutive events such as storm surges, floods, and landslides. Most currently available models do not allow for a thorough representation and analysis of these secondary events and impacts (De Ruiter et al., 2020). However, Typhoon Haiyan demonstrated the importance of having more and clearer information on these secondary effects. Unclear communication about the impacts of the storm surge associated with Haiyan had a fatal outcome: "In Tacloban...they [the Philippine Atmospheric, Geophysical, and Astronomical Services Administration] made mention of the secondary hazards in technical terms, but people did not understand." Potential users therefore stated that they hoped this new forecasting model could change this. The impact-based forecasting model has included two predictors on settlements at risk of landslides and at risk of storm surge based on data from the Nationwide Operational Assessment of Hazards (Project NOAH).

\section{Discussion and Conclusion}

The impact-based forecasting model that is central in this article is part of a promising EWS approach that requires 
extensive atmospheric modelling based on technological interventions. International organizations including the Red Cross invested in people-centred, communitybased, and community-managed approaches to ensure such EWSs have a shared ownership. The new generation of EWSs that is central inthis article is promising, since it aims to more effectively save lives and livelihoods on the basis of forecasts followed by early action. Yet, to put an impact-based forecasting model into practice is challenging because of the complexity of weather forecasts themselves and because of the social-political context in which it is introduced. In this article, we explored the design, transfer, and implementation of 510's model through three lenses: legitimacy, accountability, and local ownership.

First, the German Red Cross undertook several measures with the Philippine Red Cross to increase legitimacy within the Red Cross by involving local organizations and actors in the development process of forecastbased financing over the span of about two and a half years. 510's activities were a small part of these overall efforts, and most activities by its software developers were done remotely with only a few short field missions. An initial mission assessed the need for a priority index model, a predecessor of their impact-based forecasting model, and later, co-design sessions were organized to determine the user needs of decision makers who would be using the model. Insights from such sessions could help programmers to especially understand the requirements for a future user interface. The sessions helped the project team better understand the needs at the Manila headquarters level but less so at the local level. The efforts to reach legitimacy with the government proved more complex because the Philippine Atmospheric, Geophysical, and Astronomical Services Administration was very reluctant to collaborate.

Second, some humanitarian organizations seemed to include forecast-based financing to improve their upward accountability towards donors rather than to improve downward accountability. Humanitarian agencies are part of a competitive market in which agencies tend to favour projects that are likely to raise funds (Hilhorst, 2018). 510 is a part of these market mechanisms. However, in the Philippines, the forecastbased financing project had already started and 510 was approached only when the elementary rule-based triggers proved to be challenging to design. Generally, 510's decision matrix suggests participation in an external donor tendering process only if there is a clear need expressed by a local Red Cross National Society. Tensions can exist between a belief in technological solutions to solve societal problems and the harsh reality on the ground where, for example, sufficient data may not be available. Because 510 does not organize interventions on the ground, the initiative does not measure its downward accountability to the community level.

Third, we found that, even though local stakeholders proclaimed the benefits of impact-based forecast- ing models compared to traditional weather forecasting models in general, they did not-at the time of the research-have a clear understanding of the benefits and limitations of the model specifically developed for their context. The Philippine Atmospheric, Geophysical, and Astronomical Services Administration is developing their own impact-based forecasting model, but they have not shared much about what this model can and cannot do. The clear protocols of the Philippine Red Cross and the strict mandating of organizations by the local government can be seen as attempts to maintain local ownership over the planning and design of humanitarian interventions. Such attempts are an indication that local ownership over the modelling of impacts is indeed possible yet difficult in the social-political context of the Philippines.

Overall, we conclude that for 510's an impact-based forecasting model to be successful, it should ideally be the outcome of co-creation at the requirement and user interface design. Also, our findings imply that the exchange of knowledge between the designer and manufacturer of impact-based models and the end users of those models is not just a matter of transfer; it should be based on the creation of a mutual understanding about the users' needs and and how innovative EWS such as forecast-based financing models should be shaped and used as opposed to the traditional way of working/traditional forecasting methods. On the basis of our research, we recommend that the design, transfer, and implementation of an Early Warning System making use of an impact-based forecasting model should go beyond stakeholder analysis and be based on a clear understanding of the power relations in order to meet the needs and interests at all levels.

\section{Acknowledgments}

Sterre Bierens, from the Vrije Universiteit Amsterdam, conducted fieldwork in the Philippines for the project on developing an impact-based forecasting model commissioned by the German Red Cross. Marc van den Homberg, from 510, an initiative of the Netherlands Red Cross and Kees Boersma (Vrije Universiteit Amsterdam) supported the design and subsequent analysis of the fieldwork. Kees Boersma also took part in 510 workgroup meetings organized by Marc van den Homberg in the Hague at the Netherlands Red Cross headquarters. The authors could re-use and analyze the data from the codesign sessions, with permission of the German Red Cross, for the independent research described in this academic article. We are very grateful to the German Red Cross for the generous use of the data. We have highly appreciated the opportunity to base our article on interactions on many occasions and levels between the authors and the community of practice around the German Red Cross. The authors gratefully acknowledge Damien Riquet, the German Red Cross forecast-based financing project manager based in Manila, for his invalu- 
able support in organizing the fieldwork, and our interviewees, for so generously making time to provide us with their insights. Furthermore, the authors would like to thank Orla Canavan (510, an initiative of The Netherlands Red Cross) for her extensive knowledge of co-design sessions and for her support in organizing our sessions for this research. Marc van den Homberg was partly supported by the Netherlands Red Cross Princess Margriet Fund.

\section{Conflict of Interests}

The authors declare no conflicts of interest.

\section{References}

Aitsi-Selmi, A., Sasaki, H., Wannous, C., Murray, V., \& Egawa, S. (2015). The Sendai Framework for Disaster Risk Reduction: Renewing the global commitment to people's resilience, health, and well-being. International Journal of Disaster Risk Science, 6(2), 164-176.

Alcayna, T., Bollettino, V., Dy, P., \& Vinck, P. (2016). Resilience and disaster trends in the Philippines: Opportunities for national and local capacity building. PLoS Currents. https://doi.org/10.1371/currents.dis. 4a0bc960866e53bd6357ac135d740846

Baharmand, H., Boersma, F. K., Meesters, K., Mulder, F., \& Wolbers, J. J. (2016). A multidisciplinary perspective on supporting community disaster resilience in Nepal. In A. Tapia, P. Antunes, V. A. Bañuls, K. Moore, \& J. Porto (Eds.), Proceedings of the ISCRAM 2016 conference (pp. 2-12). Rio de Janeiro: Federal University of Rio de Janeiro.

Balcik, B., Beamon, B. M., \& Smilowitz, K. (2008). Last mile distribution in humanitarian relief. Journal of Intelligent Transportation Systems, 12(2), 51-63.

Bankoff, G., Frerks, G., \& Hilhorst, T. (2004). Mapping vulnerability: Disasters, development and people. London and New York, NY: Earthscan.

Barnett, M. (2013). Humanitarian governance. Annual Review of Political Science, 16, 379-398.

Barnett, M., \& Duvall, R. (2005). Power in international politics. International Organization, 59(1), 39-75.

Basher, R. (2006). Global early warning systems for natural hazards: Systematic and people-centred. Philosophical Transactions of the Royal Society A: Mathematical, Physical and Engineering Sciences, 364(1845), 2167-2182.

Battista, F., \& Baas, S. (2004). The role of local institutions in reducing vulnerability to recurrent natural disasters and in sustainable livelihoods development. Rome: Food and Agriculture Organization.

Biesbroek, G. R., Termeer, C. J., Klostermann, J. E., \& Kabat, P. (2014). Analytical lenses on barriers in the governance of climate change adaptation. Mitigation and Adaptation Strategies for Global Change, 19(7), 1011-1032.

Blanco, D. V. (2015). Disaster governance in the Philippines: Issues, lessons learned, and future directions in the post-Yolanda super typhoon aftermath. International Journal of Public Administration, 38(10), 743-756.

Boeke, S., van den Homberg, M. J. C., Teklesadik, A., Fabila, J. L. D., Riquet, D., \& Alimardani, M. (2019). Towards predicting rice loss due to typhoons in the Philippines. The International Archives of Photogrammetry, Remote Sensing and Spatial Information Sciences, 42, 63-70.

Bryman, A. (2012). Social research methods. Oxford: Oxford University Press.

Choi, H. J. (2009). Technology transfer issues and a new technology transfer model. Journal of Technology Studies, 35(1), 49-57.

Cools, J., Innocenti, D., \& O’Brien, S. (2016). Lessons from flood early warning systems. Environmental Science \& Policy, 58, 117-122.

De Perez, E. C., van den Hurk, B., van Aalst, M., Jongman, B., Klose, T., \& Suarez, P. (2015). Forecastbased financing: An approach for catalyzing humanitarian actrion based on extreme weather and climate forecasts. Natural Hazards and Earth System Sciences, 15, 895-904. https://doi.org/10.5194/nhess15-895-2015

De Ruiter, M. C., Couasnon, A., van den Homberg, M. J. C., Daniell, J. E., Gill, J. C., \& Ward, P. J. (2020). Why we can no longer ignore consecutive disasters. Earth's Future, 8(3). https://doi.org/10.1029/2019EF001425

Dekens, J. (2007). Part 1: Background. In J. Dekens (Ed.), Local knowledge for disaster preparedness: A literature review (pp. 1-17). Kathmandu: International Centre for Integrated Mountain Development.

Dongeren, A. v., Ciavola, P., Viavattene, C., De Kleermaeker, S., Martinez, G., Ferreira, O., \& McCall, R. (2014). RISC-KIT: Resilience-increasing strategies for coast-toolkit. In A. Green \& J. Cooper (Eds.), Proceedings of the 13th international coastal symposium (pp. 366-371). Durban: Journal of Coastal Research.

Ebrahim, A. (2003). Accountability in practice: Mechanisms for NGOs. World Development, 31(5), 813-829.

Ewbank, R., Perez, C., Cornish, H., Worku, M., \& Woldetsadik, S. (2019). Building resilience to El Niño-related drought: Experiences in early warning and early action from Nicaragua and Ethiopia. Disasters, 43, 345-367.

Frazier, T., Walker, M., Kumari, A., \& Thompson, C. (2013). Opportunities and constraints to hazard mitigation planning. Applied Geography, 40, 52-60.

Gioia, D. A., Corley, K. G., \& Hamilton, A. L. (2013). Seeking qualitative rigor in inductive research: Notes on the Gioia methodology. Organizational Research Methods, 16(1), 15-31.

Hammersley, M., \& Atkinson, P. (2007). Ethnography: Principles in practice. London: Routledge.

Heintze, H., Kirch, L., Küppers, B., Mann, H., Mischo, F., Mucke, P., . . . Welle, D. (2018). World risk report. Bochum: Bündnis Entwicklung Hilft. 
Hilhorst, D. (2018). Classical humanitarianism and resilience humanitarianism: Making sense of two brands of humanitarian action. Journal of International Humanitarian Action, 3(1), 1-12.

Madianou, M., Longboan, L., \& Ong, J. C. (2015). Finding a voice through humanitarian technologies? Communication technologies and participation in disaster recovery. International Journal of Communication, 9, 3020-3038.

Maskrey, A. (2011). Revisiting community-based disaster risk management. Environmental Hazards, 10, 42-52.

Maskus, K. E. (2004). Encouraging international technology transfer (Vol. 7). Geneva: ICTSD.

Mechler, R., Bouwer, L. M., Linnerooth-Bayer, J., Hochrainer-Stigler, S., Aerts, J. C., Surminski, S., \& Williges, K. (2014). Managing unnatural disaster risk from climate extremes. Nature Climate Change, 4(4), 235.

Mulder, F., \& Boersma, F. K. (2017). Linking up the last mile: How humanitarian power relations shape community e-resilience. In T. Comes, F. Bénaben, C. Hanachi, M. Lauras, \& A. Montarnal (Eds.), Proceedings of the ISCRAM conference (pp. 715-725). Albi: IMT Mines Albi.

Mulder, F., Ferguson, J., Groenewegen, P., Boersma, K., \& Wolbers, J. (2016). Questioning big data: Crowdsourcing crisis data towards an inclusive humanitarian response. Big Data \& Society, 3(2). https://doi. org/10.1177/2053951716662054

Nahar, N., Lyytinen, K., Huda, N., \& Muravyov, S. V. (2006). Success factors for information technology supported international technology transfer: Finding expert consensus. Information \& Management, 43(5), 663-677.

Narkunas, J. (2015). Human rights and states of emergency: Humanitarians and governmentality. Culture, Theory and Critique, 2, 208-227.

NDRRMC. (2019). Revised guidelines for the declaration of a state calamity (Memorandum 60). Quezon: NDRRMC. Retrieved from https://www. officialgazette.gov.ph/downloads/2019/06jun/ 20190617-NDRRMC-MO-60-RRD.pdf

Ossewaarde, R., Nijhof, A., \& Heyse, L. (2008). Dynamics of NGO legitimacy: How organising betrays core missions of INGOs. Public Administration and Development, 28, 42-53.

Parker, A., \& Tritter, J. (2006). Focus group method and methodology: Current practice and recent debate. International Journal of Research \& Method in Education, 29(1), 23-37.

Philippine Red Cross. (2019). Forecast-based financing early action protocol TYPHOON Philippines. Mandaluyong: Philippine Red Cross. Retrieved from http://adore.ifrc.org/Download.aspx?Fileld=288199

Porio, E. (2017). Citizen participation and decentralization in the Philippines. In W. Berenschot, H. H. S. Nordholt, \& L. Bakker (Eds.), Citizenship and democ- ratization in Southeast Asia (pp. 29-50). Leiden: Brill. Rai, R. K., van den Homberg, M. J. C., Ghimire, G. P., \& McQuistan, C. (2020). Cost-benefit analysis of flood early warning system in the Karnali River Basin of Nepal. International Journal of Disaster Risk Reduction. https://doi.org/10.1016/j.ijdrr.2020.101534

Red Cross. (2018). A guide to trigger methodology for forecast-based financing. Geneva: Red Cross. Retrieved from http://forecast-basedfinancing.drk. de/fileadmin/user_upload/Forecast-basedfinancing _Manual_A_guide_to_trigger_methodology.pdf

Ritchie, J., Lewis, J., McNaughton Nicholls, C., \& Ormston, R. (2013). Qualitative research practice: A guide for social science students and researchers. London: Sage.

Rogers, D., \& Tsirkunov, V. (2010). Global assessment report on disaster risk reduction: Costs and benefits of early warning systems. Washington, DC: World Bank.

Sanders, E. B. N., Brandt, E., \& Binder, T. (2010). A framework for organizing the tools and techniques of participatory design. In T. Robertson, K. Bodker, T. Bratteteig, \& D. Loi (Eds.), Proceedings of the 11th biennial participatory design conference (PDC '10) (pp. 195-198). New York, NY: Association for Computing Machinery.

Santos, A. L. R., Capet, L., \& Diehl, J. C. (2013). The value of collaborative design to address the challenges of the humanitarian sector. In A. A. Fernandes, R. M. Natal Jorge, L. Patrício, \& A. Medeiros (Eds.), Proceedings of the 3rd international conference on integration of design, engineering and management for innovation (pp. 301-310). Porto: IDEMi.

Sleeswijk Visser, F., Van der Lugt, R., \& Stappers, P. J. (2007). Sharing user experiences in the product innovation process: Participatory design needs participatory communication. Creativity and Innovation Management, 16(1), 35-45.

Steffek, J., \& Hahn, K. (Eds.). (2010). Evaluating transnational NGOs: Legitimacy, accountability, representation. New York, NY: Palgrave.

Strauss, A., \& Corbin, J. (1990). Basics of qualitative research. London: Sage.

UNDRR. (2020). Terminology. UNDRR. Retrieved from https://www.undrr.org/terminology\#V

UNEP. (2012). Early Warning Systems: A state of the art analysis and future directions. Nairobi: Division of Early Warning and Assessment of the United Nations Environment Programme.

Unerman, J., \& O'Dwyer, B. (2010). NGO accountability and sustainability issues in the changing global environment. Public Management Review, 12(4), 475-486.

UNISDR. (2013). Annual report: Final report on 2012-2013 biennium work programme. Geneva: United Natons Office for Disaster Risk Reduction.

UNISDR. (2015a). Hyogo Framework for Action 2005-2015: Building the resilience of nations 
and communities to disasters. Geneva: United Nations.

UNISDR. (2015b). Sendai Framework for Disaster Risk Reduction 2015-2030. Geneva: United Nations.

van den Homberg, M. J. C., \& McQuistan, C. (2019). Technology for climate justice: A reporting framework for loss and damage as part of key global agreements. In R. Mechler, L. M. Bouwer, T. Schinko, \& S. Surmins$\mathrm{ki}$ (Eds.), Loss and damage from climate change (pp. 513-545). Springer: Cham.

Van Lint, S. (2016). Sense-making of the Netherlands Red Cross Priority Index model: Case typhoon Haiyan, Philippines (Masters dissertation). Wageningen University, The Netherlands. Retrieved from https:// edepot.wur.nl/421814

Von Hippel, E. (2005). Democratizing innovation: The evolving phenomenon of user innovation. The State of The Art Article, 55, 63-78.
Wagenaar, D., Hermawan, T., van den Homberg, M. J. C., Aerts, J. C. J. H., Kreibich, H., de Moel, H., \& Bouwer, L. M. (2020). Improved transferability of data-driven damage models through sample selection bias correction. Risk Analysis. https://doi.org/10.1111/risa. 13575

Williams, R., \& Edge, D. (1996). The social shaping of technology. Research Policy, 25(6), 865-899.

World Meteorological Organization. (2015). Guidelines on multi-hazard impact-based forecast and warning services. Geneva: World Meteorological Organization.

Yanow, D., \& Schwartz-Shea, P. (2015). Interpretation and method: Empirical research methods and the interpretive turn. London: Routledge.

Zschau, J., \& Küppers, A. N. (Eds.). (2013). Early warning systems for natural disaster reduction. Cham: Springer Science \& Business Media.

\section{About the Authors}
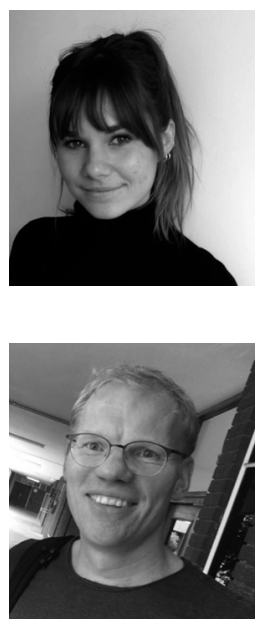

Sterre Bierens (MSc) studied the Master's Culture, Organization and Management at the Faculty of Social Sciences of the Vrije Universiteit Amsterdam. Her thesis is called Advocating Humanitarian Collaboration: How the Neglect of Local Context Challenges the Implementation of Innovative Disaster Risk Reduction Strategies. She performed fieldwork in the Philippines at the Red Cross in Manila where she studied the implementation and use of Early Warning Systems. Currently she works a Consultant on energy sustainability and hydrogen risk and safety standardization at the Royal NEN.

Kees Boersma (PhD) is Associate Professor and Research Manager at the Vrije Universiteit Amsterdam in the department of Organization Sciences. His research interest is in crisis management, disaster studies, and innovation management. He is Co-Founder of the Crisis Resilience Academy of the Institute for Societal Resilience. His current projects include: The EU Horizon 2020 project "LINKS: Strengthening links between technologies and society for European disaster resilience," and the EU Horizon 2020 Covid-19 project "HERoS: Health Emergency Response in Interconnected Systems" (WP Leader). He is Vice President of the the Information Systems for Crisis Response and Management association. He was Visiting Scholar at Johns Hopkins University and the University of Illinois at Urbana-Champaign and at the Disaster Management Training and Education Centre for Africa (DiMTEC) of the University of the Free State in South Africa.

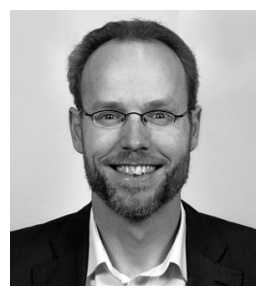

Marc J. C. van den Homberg (PhD) leads the research activities of 510, an initiative of the Netherlands Red Cross to support Red Cross National Societies in developing countries. His research concerns improving preparedness and response to both natural hazards and complex emergencies through datadriven risk assessments, impact-based forecasting, information management, and disaster risk governance. Before 510, Marc was the Leader and Co-Founder of the Netherlands Research and Technology Organization's (TNO) ICT for Development team. Marc holds the Disaster Management Certificate from IFRC/Tata Institute of Social Sciences, an MBA from Rotterdam School of Management, and a PhD in physics from Delft University of Technology. 